Check for updates

Cite this: RSC Adv., 2017, 7, 21809

Received 9th March 2017

Accepted 13th April 2017

DOI: $10.1039 / \mathrm{c} 7 \mathrm{ra02848b}$

rsc.li/rsc-advances

\section{A silicon photoanode for efficient ethanol oxidation under alkaline conditions $\uparrow$}

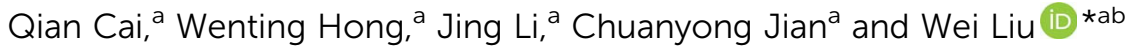

Silicon ( $\mathrm{Si}$ ) is an attractive semiconductor which has broad applications in photovoltaic fields due to its low cost and narrow band gap ( 1.1 eV). Taking advantage of a Si-based metal-insulator-semiconductor (MIS) device, which has high electron-hole separation efficiency due to the confined electron and hole transport directions, for the first time, a Pt/ $\mathrm{ZrO}_{2} / \mathrm{n}$-Si photoanode is directly employed as the anode for the ethanol oxidation reaction (EOR). When exposed to visible light irradiation, the $\mathrm{Pt} / \mathrm{ZrO}_{2} / \mathrm{n}$-Si photoanode exhibits apparently improved EOR activity and durability. This work provides a simple way to fabricate Si-based EOR photoanodes, which has potential for application in direct ethanol fuel cells.

\section{Introduction}

Direct ethanol fuel cells (DEFCs) have attracted enormous attention as efficient devices for converting chemical energy into electrical energy with high power density output and low pollutant emissions..$^{1-3}$ Compared with methanol, ethanol has the advantages of low toxicity and high theoretical energy density $\left(8.01 \mathrm{~kW} \mathrm{~h} \mathrm{~kg}^{-1}\right) \cdot{ }^{4-6}$ However, the relatively slow kinetics for the ethanol oxidation reaction (EOR) becomes a major obstacle for the development of efficient DEFCs. ${ }^{7,8}$ Currently, the precious metal platinum $(\mathrm{Pt})$ has been considered to be the most promising electrocatalyst for the EOR. Considerable effort has been spent to disperse $\mathrm{Pt}$ nanoparticles on various substrates, such as metal oxides $\left(\mathrm{MnO}_{2}, \mathrm{SnO}_{2}\right)$ and carbon (graphene, CNT) ${ }^{9,10}$ to enhance the EOR performance and reduce the usage of Pt. Combining Pt nanoparticles with photoactive semiconductors $\left(\mathrm{ZnO}, \mathrm{TiO}_{2}\right)$ is another option to improve the EOR performance, which has been demonstrated to be an effective way to boost the EOR performance using solar energy. ${ }^{11-13}$ Under illumination, the semiconductor generates many electron-hole pairs that can be utilized to oxidize organic molecules efficiently.

Silicon (Si) is an attractive semiconductor which has broad applications in photovoltaic fields due to its low cost and narrow band gap $(\sim 1.1 \mathrm{eV}) .{ }^{14}$ In addition, Si photoanodes have shown promising properties for water oxidation reaction. ${ }^{15-18}$ Usually, Si is integrated into a metal-insulator-semiconductor (MIS) device, in which Si server as the light absorber. The most

${ }^{a}$ Key Laboratory of Design and Assembly of Functional Nanostructures, Fujian Institute of Research on the Structure of Matter, Chinese Academy of Sciences, Fuzhou, 350002, China.E-mail:Liuw@fjirsm.ac.cn

${ }^{b}$ Fujian Provincial Key Laboratory of Nanomaterials, Fujian Institute of Research on the Structure of Matter, Chinese Academy of Sciences, Fuzhou, 350002, China

$\dagger$ Electronic supplementary information (ESI) available. See DOI: 10.1039/c7ra02848b advantage of using Si-based MIS device is the high electronhole separation efficiency due to the confined electron and hole transport directions (Fig. 1a). Although various Si photoanodes have been studied for water oxidation reaction, there is no study about employing Si as photocatalyst combines with Pt electrocatalysts for EOR with the assistance of solar energy.

Herein, we report a Si photoanode for high-performance EOR. Instead of using $\mathrm{TiO}_{2}$ as the protective layer, a thin $\mathrm{ZrO}_{2}$ layer $(2 \mathrm{~nm})$ was deposited by atomic layer deposition (ALD) method. The thin $\mathrm{ZrO}_{2}$ layer not only serves as a conventional passivation layer to prevent $\mathrm{Si}$ corrosion but also acts as an insulating layer to form "electron filter" for holes transport. Finally, Pt nanoparticles are deposited onto $\mathrm{ZrO}_{2}$ surface by electron beam evaporation method. The fabricated $\mathrm{Pt} / \mathrm{ZrO}_{2} / \mathrm{n}-\mathrm{Si}$ with a metal-insulator-semiconductor (MIS) architecture (Fig. 1a) can be directly employed as the anode for EOR without the additional catalyst dispersion procedure. This simple fabrication process can suppress the Pt nanoparticles aggregation, thereby maintaining the catalytic activity of Pt nanoparticles. Our results exhibit that the $\mathrm{Pt} / \mathrm{ZrO}_{2} / \mathrm{n}$-Si anode has

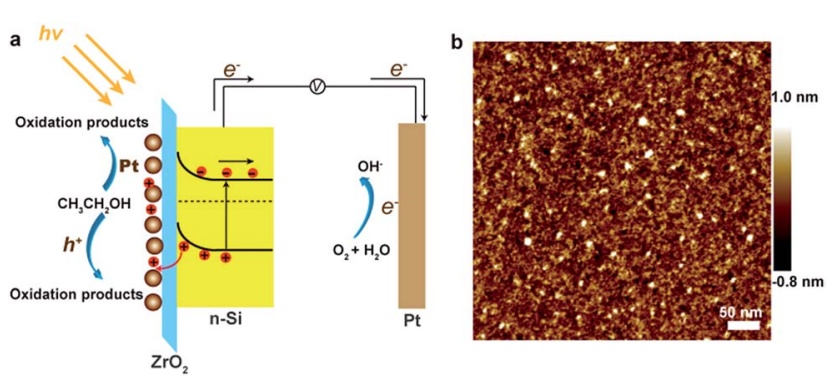

Fig. 1 (a) Schematic diagram of photo-assisted electrocatalytic EOR for $\mathrm{Pt} / \mathrm{ZrO}_{2} / \mathrm{n}-\mathrm{Si}$ anode with front illumination. (b) Atomic force microscopy (AFM) image of the surface of $\mathrm{Pt} / \mathrm{ZrO}_{2} / \mathrm{n}-\mathrm{Si}$ anode. The deposition thickness set point of Pt thickness is $2 \mathrm{~nm}$. 
excellent EOR properties even in the dark. When $\mathrm{Pt} / \mathrm{ZrO}_{2} / \mathrm{n}-\mathrm{Si}$ anode exposed to the visible light irradiation, the anode shows significantly improved EOR performance and durability.

\section{Experimental}

\subsection{Chemicals}

All materials were used as received, except where otherwise noted.

\subsection{Preparation of $\mathrm{Pt} / \mathrm{ZrO}_{2} / \mathrm{n}$-Si anode}

Single side polished P-doped (100) n-type Si wafer with a resistivity of $0.5 \Omega \mathrm{cm}^{-1}$ were employed. For $\mathrm{Pt} / \mathrm{ZrO}_{2} / \mathrm{n}$-Si photoanode fabrication, Si wafer is dipped into buffered HF for 2 minutes to remove native oxide completely. Subsequently, the Si wafer is cleaned by deionized water and loaded into the ALD chamber for $\mathrm{ZrO}_{2}$ deposition. $\mathrm{ZrO}_{2}$ layer was deposited by Oxford Instruments FlexAL ALD on the fresh etched $\mathrm{Si}$ substrates. The ALD were conducted at $200{ }^{\circ} \mathrm{C}$ with the tetrakis(ethylmethylamino)zirconium (TEMAZ) as $\mathrm{Zr}$ precursor and water vapor as an oxygen source. $\mathrm{N}_{2}$ was used as carrier gas. Each source was heated to a line temperature of $80{ }^{\circ} \mathrm{C}$. The pulse time of TEMAZ and water was $5 \mathrm{~s}$ and $0.7 \mathrm{~s}$, respectively. The equilibrium purge pressure was approximately 600 mTorr. The deposition rate was maintained $0.6 \AA$ per cycle, 16 cycles of ALD was performed make the thickness of $\mathrm{ZrO}_{2}$ up to $2 \mathrm{~nm}$. Finally, Pt nanoparticles were deposited by electron beam evaporation in the vacuum of $5 \times 10^{-7}$ Torr. The deposition rate (0.2 ̊ per second) and thickness (deposition set point) of Pt nanoparticles were monitored by resonating quartz crystal sensor. Finally, $10 \mathrm{~nm} / 100 \mathrm{~nm}$ (Ti/Au) film was deposited on the backside of $\mathrm{Pt} / \mathrm{ZrO}_{2} / \mathrm{n}$-Si photoanode to create an ohmic contact by electron beam evaporation.

\subsection{Morphology and composition characterization}

Atomic force microscopy (AFM) images were collected with a Bruker Dimension Icon operating in ScanAsyst mode using Bruker ScanAsyst-Air probes (silicon tip; silicon nitride cantilever, spring constant: $0.4 \mathrm{~N} \mathrm{~m}^{-1}$, frequency: $70 \mathrm{kHz}$ ). The images were analyzed using NanoScope Analyst software (version 1.40). XPS measurements were conducted using a PHI VersaProbe system, equipped with a $100 \mathrm{~W}$ Al K $\alpha$ source on a spot size of $100 \mu \mathrm{m}$ at a $45^{\circ}$ incident angle. The binding energy scan range was $0-1200 \mathrm{eV}$ in $1 \mathrm{eV}$ steps, high-intensity excitation was provided by monochromatic Al K X-rays that were $1486.6 \mathrm{eV}$ in energy with a $0.2 \mathrm{eV}$ resolution at full width at half-maximum. Each data set was first corrected for the nonlinear emission background. The data was then fitted with Gaussian function to find the deconvoluted peak positions.

\subsection{Photoelectrochemical characterization}

All electrochemical measurements are performed on a CHI 660e electrochemical workstation with a standard three-electrode cell at room temperature. The As-prepared $\mathrm{Pt} / \mathrm{ZrO}_{2} / \mathrm{Si}$ is used directly as the working anode without further treatments. Pt wire is used as the counter electrode. The $\mathrm{Ag} / \mathrm{AgCl}$ electrode filled with $3.5 \mathrm{M} \mathrm{KCl}$ serves as the reference electrode. Cyclic voltammograms (CVs) of the prepared $\mathrm{Pt} / \mathrm{ZrO}_{2} / \mathrm{Si}$ anode was measured in the range of $-0.2 \mathrm{~V}$ to $0.4 \mathrm{~V}$ versus $\mathrm{Ag} / \mathrm{AgCl}$ with a scan rate of $50 \mathrm{mV} \mathrm{s}^{-1}$ with and without visible light irradiation. A xenon lamp with an UV cutoff filter was employed as an excitation source, with intensity of $100 \mathrm{~mW} \mathrm{~cm}{ }^{-2}$ simulated 1 sun AM 1.5 illumination. The front illumination is used in the photo-assisted catalytic process. Before data was recorded, the anodes were pre-scanned for 50 cycles until a stable CVs curve was developed. And the onset potential is defined as the potential at the current density of $1 \mathrm{~mA} \mathrm{~cm}^{-2}$. Electrochemical Impedance Spectroscopy (EIS) measurements were recorded from $100 \mathrm{kHz}$ to $10 \mathrm{MHz}$ at an $\mathrm{AC}$ signal of $10 \mathrm{mV}$.

\section{Results and discussion}

In this work, $\mathrm{Pt} / \mathrm{ZrO}_{2} / \mathrm{n}$-Si anode is fabricated using conventional complementary metal oxide semiconductor (CMOS) fabrication technology as described in the Experimental section and Fig. S1. $\dagger$ Fig. 1a represents the band diagram of $\mathrm{Pt} / \mathrm{ZrO}_{2} / \mathrm{n}$ Si photoanode without bias under front illumination. After absorbing solar photons, photo-generated electron-hole pairs are created on the surface of Si. High work function metal catalysts (Pt) form a Schottky barrier with n-type Si. Holes tunnel through the $\mathrm{ZrO}_{2}$ layer and finally reach the metal catalyst to oxidize ethanol molecules. AFM image (Fig. 1b) displays that the deposited Pt nanoparticles cannot form continuing film. The deposition thickness set point of Pt thickness is $2 \mathrm{~nm}$. According to the AFM image, the thickness and diameter of the deposited Pt nanoparticles were analyzed to be $1.94 \mathrm{~nm}$ and $6.6 \mathrm{~nm}$ (Fig. S2 $\dagger$ ), respectively, indicates that electron beam deposition method can produce small nanoparticles for high-performance EOR process with low cost. In addition, the ultra-thin Pt layer will not significantly affect the light absorption of the Si substrate (Fig. S3†).

The ethanol electro-oxidation performance of as-prepared $\mathrm{Pt} / \mathrm{ZrO}_{2} / \mathrm{n}$-Si anode was investigated by electrochemical characterization. Fig. 2a shows the typical cyclic voltammograms (CVs) curves of the $\mathrm{Pt} / \mathrm{ZrO}_{2} / \mathrm{n}$-Si anode operated in $1.0 \mathrm{M} \mathrm{KOH}$ solutions at a sweep rate of $50 \mathrm{mV} \mathrm{s}^{-1}$ with (red line) and without (black line) 1.0 M ethanol. In the absence of ethanol, the CVs curve exhibits a broad oxidation peak in the region of $0.2-0.3 \mathrm{~V}$, which is due to the formation of surface Pt-oxide by the adsorption of $\mathrm{OH}^{-}$ions. ${ }^{19}$ In the reverse sweeping scan, the reduction peak appears at $0.08 \mathrm{~V}$, corresponding to the Pt-oxide reduction. When $1.0 \mathrm{M}$ ethanol was added into the $1.0 \mathrm{M} \mathrm{KOH}$ solution, the CVs curves are dramatically changed. The peak appears at $0.17 \mathrm{~V}$, and reaches a maximum current density of $11.08 \mathrm{~mA} \mathrm{~cm}{ }^{-2}$, which corresponds to the oxidation peak of ethanol. The large current density represents the high electrocatalytic activity of the $\mathrm{Pt} / \mathrm{ZrO}_{2} / \mathrm{n}$-Si anode for EOR. For the reverse scan, the reduction peak appeared at $0.07 \mathrm{~V}$ is attributed to the removal of incompletely oxidized carbonate species absorbed on the Pt surface.

The impact of scan rates on the EOR activity for $\mathrm{Pt} / \mathrm{ZrO}_{2} / \mathrm{n}-\mathrm{Si}$ anode is shown in Fig. 2 b. The peak current density is linearly proportional to the square root of scan rates (inset of Fig. 2b), 

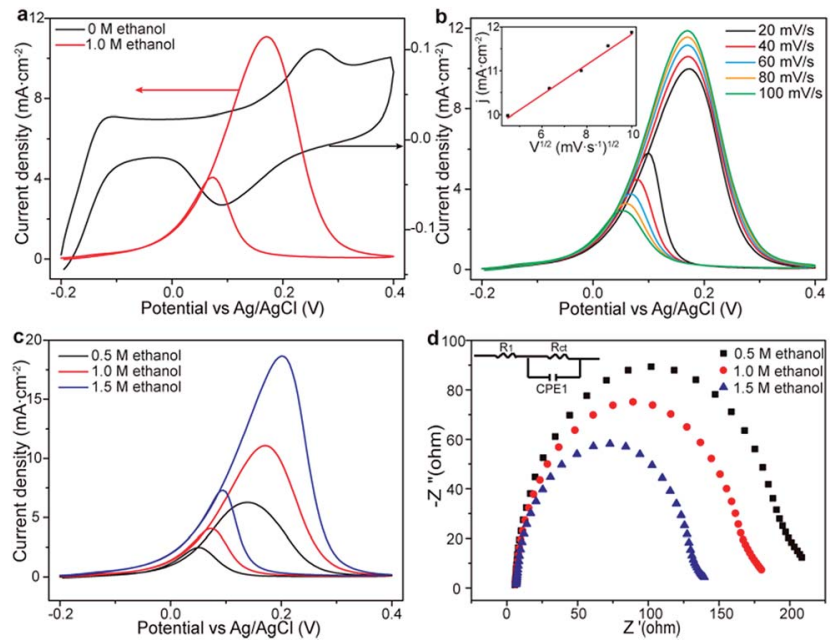

Fig. 2 EOR test of $\mathrm{Pt} / \mathrm{ZrO}_{2} / \mathrm{n}-\mathrm{Si}$ anode in the dark. (a) Typical CVs curves of $\mathrm{Pt} / \mathrm{ZrO}_{2} / \mathrm{n}$-Si anode in $1.0 \mathrm{M} \mathrm{KOH}$ solution at a scan rate of $50 \mathrm{mV} \mathrm{s}^{-1}$ with (red line) and without (black line) $1.0 \mathrm{M}$ ethanol. (b) CVs curves of $\mathrm{Pt} / \mathrm{ZrO}_{2} / \mathrm{n}-\mathrm{Si}$ anode in $1.0 \mathrm{M} \mathrm{KOH}$ and $1.0 \mathrm{M}$ ethanol at different scan rates. The inset shows a linear relationship of current density with the square root of scan rate. (c) CVs curves of $\mathrm{Pt} / \mathrm{ZrO}_{2} / \mathrm{n}$ $\mathrm{Si}$ anode in $1.0 \mathrm{M} \mathrm{KOH}$ with different ethanol concentration. (d) The Nyquist plots, the inset shows the equivalent circuit model.

which is the characteristic of a diffusion controlled process limited by the diffusion of ethanol or the reaction intermediates. ${ }^{20}$ Moreover, to explicitly confirm the oxidation of ethanol at the $\mathrm{Pt} / \mathrm{ZrO}_{2} / \mathrm{n}$-Si anode, the $\mathrm{CVs}$ curves were recorded at different ethanol concentrations in $1.0 \mathrm{M} \mathrm{KOH}$ electrolyte (Fig. 2c). Along with the increase of ethanol concentration, the oxidation current density is significantly enhanced, indicating that ethanol undergoes efficiently catalytic oxidation at the anode. Meanwhile, the electrochemical impedance spectroscopy (EIS) is also performed to analyze the interfacial charge transfer properties at the anode/electrolyte interface (Fig. 2d). Based on the one semicircle behavior in the entire frequency range from EIS data, the equivalent circuit can be modeled consists of a series resistance $\left(R_{1}\right)$, a constant phase element (CPE1), and a charge transfer resistance $\left(R_{\mathrm{ct}}\right)$ for ethanol oxidation as shown in inset of Fig. 2 d. $R_{\mathrm{ct}}$ can be described by the diameter of semicircle in the Nyquist plots, while the lower $R_{\mathrm{ct}}$ value corresponds to a faster charge transfer. Fig. $2 \mathrm{~d}$ shows that $R_{\text {ct }}$ is obviously decreased along with the increase of ethanol concentration, implying that the higher ethanol concentration can result in the faster charge transfer in the diffusion controlled process.

The visible light irradiation effect on ethanol oxidation by the as-prepared $\mathrm{Pt} / \mathrm{ZrO}_{2} / \mathrm{n}$-Si anode is also evaluated by CVs and EIS spectra measurements. Fig. 3a presents the CVs curves for the $\mathrm{Pt} / \mathrm{ZrO}_{2} / \mathrm{n}$-Si anode in $1.0 \mathrm{M} \mathrm{KOH}$ electrolyte with different amount of ethanol with light irradiation $\left(100 \mathrm{~mW} \mathrm{~cm}^{-2}\right)$. The oxidation current density keeping rising along with the increase of ethanol concentration. Fig. $3 \mathrm{~b}$ shows the comparison of the EOR performance of $\mathrm{Pt} / \mathrm{ZrO}_{2} / \mathrm{n}$-Si anode in $1.0 \mathrm{M}$ ethanol and $1.0 \mathrm{M} \mathrm{KOH}$ solution with and without visible light irradiation. It is obviously observed that the intensity of oxidation peak
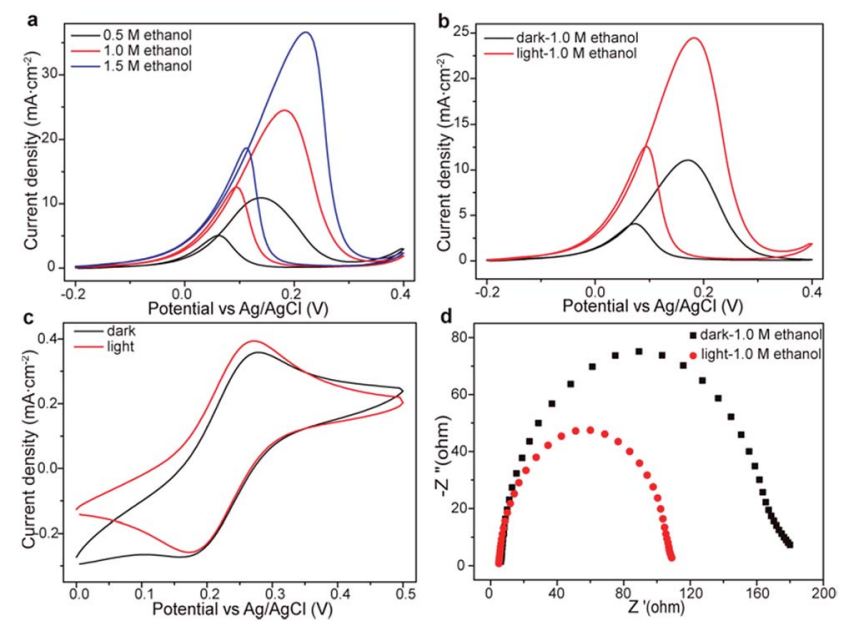

Fig. 3 (a) $\mathrm{CVs}$ of $\mathrm{Pt} / \mathrm{ZrO}_{2} / \mathrm{n}$-Si anode in $1.0 \mathrm{M} \mathrm{KOH}$ with different ethanol concentration under visible light illumination. (b) CVs of Pt/ $\mathrm{ZrO}_{2} / \mathrm{n}$-Si anode with (red line) and without (black line) light illumination in $1 \mathrm{M} \mathrm{KOH}$ containing $1.0 \mathrm{M}$ ethanol. (c) $\mathrm{CVs}$ of $\mathrm{Pt} / \mathrm{ZrO}_{2} / \mathrm{n}-\mathrm{Si}$ anode with (red line) and without (black line) light illumination in $\mathrm{Fe}(\mathrm{CN})_{6}{ }^{4-} / \mathrm{Fe}(\mathrm{CN})_{6}{ }^{3-}$ solution. (d) The Nyquist plots of $\mathrm{Pt} / \mathrm{ZrO}_{2} / \mathrm{n}-\mathrm{Si}$ anode with (red line) and without (black line) light illumination in $1 \mathrm{M}$ $\mathrm{KOH}$ containing $1.0 \mathrm{M}$ ethanol.

increase sharply in the entire potential region with visible light illumination, implying that the light irradiation improves the EOR activity. The peak current density of $\mathrm{Pt} / \mathrm{ZrO}_{2} / \mathrm{n}$-Si anode with light illumination $\left(24.46 \mathrm{~mA} \mathrm{~cm}^{-2}\right)$ is $\sim 2.21$ times higher than that in the dark $\left(11.08 \mathrm{~mA} \mathrm{~cm}{ }^{-2}\right)$. The enhancement of current density could be attributed to the synergy effect of photo- and electro-catalysis of ethanol oxidation. Additionally, the onset potential for EOR on $\mathrm{Pt} / \mathrm{ZrO}_{2} / \mathrm{n}$-Si anode under light illumination $(-0.062 \mathrm{~V})$ is lower than that measured in the dark $(-0.015 \mathrm{~V})$. Ethanol could act as a good sacrificial electron donor, and the photogenerated electron-hole pair could be separated quickly, which resulted in an enhancement of photoelectrocatalytic response and the decrease in onset potential. ${ }^{21}$ Enhanced current density and lowered onset potential indicate that $\mathrm{Pt} / \mathrm{ZrO}_{2} / \mathrm{n}$-Si anode is efficient for EOR with the assistance of visible light illumination.

The CVs curves of the reversible redox couple $K_{3}\left[\mathrm{Fe}(\mathrm{CN})_{6} /\right.$ $\left.\mathrm{K}_{4}\left[\mathrm{Fe}(\mathrm{CN})_{6}\right]\right]$ was selected as the probe to study the enhanced charge transfer efficiency during the photo-assisted electrocatalytic reaction. Fig. $3 \mathrm{c}$ illustrates the response of the reversible redox couple $\left(\mathrm{Fe}(\mathrm{CN})_{6}{ }^{4-} / \mathrm{Fe}(\mathrm{CN})_{6}{ }^{3-}\right)$ on the $\mathrm{Pt} / \mathrm{ZrO}_{2} / \mathrm{n}$-Si anode with and without light irradiation. It is observed that $\mathrm{Pt} / \mathrm{ZrO}_{2} / \mathrm{n}$-Si anode with light irradiation exhibits a higher peak current density and a lower redox potential. These results indicate the significant enhancement of the interfacial electron transfer rate between the electrolyte and anode surface with the assistance of light irradiation. ${ }^{22}$ The Nyquist plots of $\mathrm{Pt} / \mathrm{ZrO}_{2} / \mathrm{n}$ Si anode measured in $1.0 \mathrm{M} \mathrm{KOH}$ and $1.0 \mathrm{M}$ ethanol with and without illumination are shown in Fig. 3d, respectively. It is found that when $\mathrm{Pt} / \mathrm{ZrO}_{2} / \mathrm{n}$-Si anode exposed to the light, it has a much lower $R_{\text {ct }}$ value (faster interfacial charge transfer) compared with that in the dark. This phenomenon further confirms that the visible light illumination will promote the 
interfacial charge mobility and accelerate the electrocatalytic reaction rate, which is consistent with the above CVs results. The similar phenomenon is also observed on $\mathrm{Pd} / \mathrm{ZrO}_{2} / \mathrm{n}-\mathrm{Si}$ anode as shown in Fig. S4, $\uparrow$ indicating that other metal has the potential to replace Pt by using Si anode.

The catalytic durability is another important parameter for the application of electrocatalysts in fuel cells. To evaluate the EOR durability, $\mathrm{Pt} / \mathrm{ZrO}_{2} / \mathrm{n}$-Si anode is continually scanned in 1.0 M KOH electrolyte containing $1.0 \mathrm{M}$ ethanol for $4000 \mathrm{CVs}$ cycles in the dark and under illumination. The comparison of CVs curves and peak current density versus CVs cycle number is shown in Fig. 4. After 4000 cycles, $\mathrm{Pt} / \mathrm{ZrO}_{2} / \mathrm{n}$-Si anode retain the EOR activity around $92.6 \%$ and $79.3 \%$ with and without light illumination, respectively. For both conditions, the current density loss may be due to the formation of the Pt-oxide and intermediate species $\mathrm{CO}_{\text {ads }}$ poisoning on the anode surface during the early stage of EOR. ${ }^{23}$ The result indicates that photoassistance can promote the desorption of intermediate species $\mathrm{CO}_{\text {ads }}$ from Pt surface.

Based on the above discussion, the EOR electrocatalytic activity, as well as the durability for $\mathrm{Pt} / \mathrm{ZrO}_{2} / \mathrm{n}$-Si anode, is significantly improved under visible light irradiation. This improvement can be attributing to the synergistic effects of electro- and photo-catalytic during the EOR catalytic processes. When $\mathrm{Pt} / \mathrm{ZrO}_{2} / \mathrm{n}$-Si anode exposed to visible light irradiation, the photo electron-hole pairs are generated on the surface $\mathrm{Si}$ substrate (eqn (1)). The thin $\mathrm{ZrO}_{2}$ layer deposited on Si substrate serve as the electron filter, which allows for photogenerated holes tunneling through $\mathrm{ZrO}_{2}$ layer to the surface of Pt catalyst (Fig. 1a). Then, the holes can react with surface adsorbed $\mathrm{OH}^{-} /$ $\mathrm{H}_{2} \mathrm{O}$ to form high oxidative hydroxyl radicals ( $\left.{ }^{\circ} \mathrm{OH}\right)$ on the surface of catalyst (eqn (2)). ${ }^{24,25}$ The ${ }^{\circ} \mathrm{OH}$ then further oxidize the ethanol resulting in photo-assisted EOR at the anode (eqn (3)). Besides, the common carbonaceous species like $\mathrm{CO}_{\text {ads }}$ and alkoxide absorbed on the surface of catalysts, which will deactivate and poison the catalysts from further ethanol oxidation. In this photo-assisted EOR process, the highly reactive ${ }^{\circ} \mathrm{OH}$ can further oxidize the conventional carbonaceous species, thereby effectively suppressing the catalyst poisoning (eqn (4)). ${ }^{26}$ On the other hand, the photoelectrons were transported to the cathode through an external circuit, wherein oxygen was efficiently reduced. Therefore, the catalytic activity and stability toward ethanol oxidation can be both improved effectively with the assistance of visible light illumination.
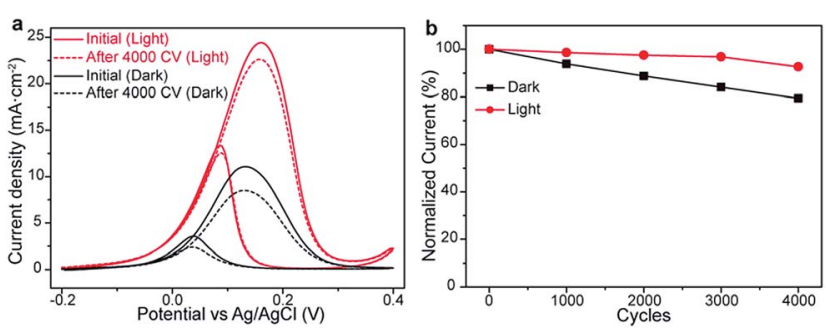

Fig. 4 The durability comparison of $\mathrm{Pt} / \mathrm{ZrO}_{2} / \mathrm{n}$-Si anode with (red line) and without (black line) visible light illumination. (a) CVs curves and (b) normalized oxidation current versus CVs cycles.
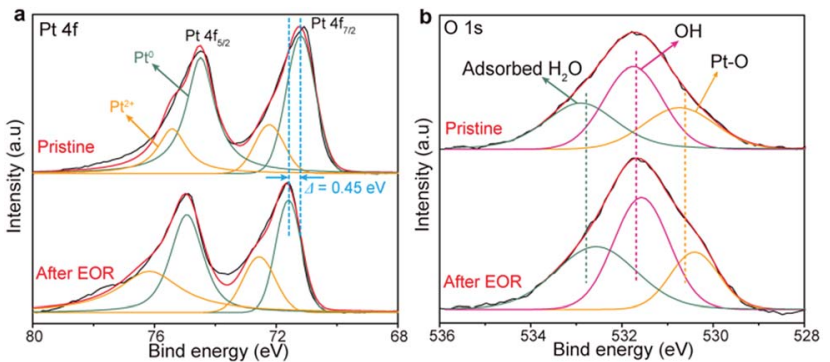

Fig. 5 XPS spectra of (a) Pt $4 \mathrm{f}$ and (b) $\mathrm{O}$ 1s of $\mathrm{Pt} / \mathrm{ZrO}_{2} / \mathrm{n}-\mathrm{Si}$ anode surface before and after ethanol oxidation reaction.

$$
\begin{gathered}
\mathrm{Si}+h \nu \rightarrow \mathrm{e}_{\mathrm{CB}}{ }^{-}+\mathrm{h}_{\mathrm{VB}}{ }^{+} \\
\mathrm{h}^{+}+\mathrm{OH}^{-} / \mathrm{H}_{2} \mathrm{O} \rightarrow \cdot \mathrm{OH} \\
\mathrm{CH}_{3} \mathrm{CH}_{2} \mathrm{OH}+\cdot \mathrm{OH} \rightarrow \mathrm{CO}_{2}+\mathrm{H}_{2} \mathrm{O}+\mathrm{e}^{-} \\
\text {Intermediate }\left(\mathrm{CH}_{3} \mathrm{CH}_{2} \mathrm{O}, \mathrm{CO}_{\mathrm{ads}}, \text { etc. }\right)+{ }^{\cdot} \mathrm{OH} \rightarrow \\
\mathrm{CO}_{2}+\mathrm{H}_{2} \mathrm{O}+\mathrm{e}^{-}
\end{gathered}
$$

The above results highlight that the formation the Pt-oxide and reaction intermediate species during the process of photo-electrooxidation of ethanol. The XPS measurements were performed on the pristine and the sample after EOR testing to investigate the elemental state. The survey XPS spectra shown in Fig. $\mathrm{S} 6 \dagger$ indicates that the anode was mainly composed of $\mathrm{Pt}, \mathrm{Zr}$, $\mathrm{O}, \mathrm{Si}$ and $\mathrm{C}$ elements. Fig. 5a displays the high-resolution Pt $4 \mathrm{f}$ core-level spectra. The peaks located at 74.48 and $71.11 \mathrm{eV}$ can be assigned to the binding energies of $P t 4 \mathrm{f}_{5 / 2}$ and $\mathrm{Pt} 4 \mathrm{f}_{7 / 2}$. The peaks can be fitted by two pairs of doublets: metallic Pt peaks (74.48 and $71.19 \mathrm{eV}$ ) and $\mathrm{Pt}^{2+}$ peaks (75.41 and $72.23 \mathrm{eV}$ ), respectively. ${ }^{11,27}$ The existence of $\mathrm{Pt}^{2+}$ peaks is the evidence of the formation of Pt-oxides, which might be due to the chemisorption of oxygen on the Pt particle. After EOR process, the Pt uf peak displayed obviously shift toward higher binding energy. Such a change may be attributed to the electron charge transfer between Pt nanoparticles and Si substrate. ${ }^{28}$ Further investigation on the O 1s XPS spectrum (Fig. 5b) reveals that three peaks corresponding to classical oxygen atoms in three different environments. Lattice oxygen (530.72 eV), dissociatively adsorbed water $(\mathrm{OH})(531.73 \mathrm{eV})$, and surface-absorbed water (532.89 eV) can be observed in Fig. $5 b .{ }^{29}$ The positions peaks are slightly changed after the EOR test due to the oxidation of Pt particles during the EOR test.

\section{Conclusions}

In summary, for the first time, $\mathrm{Pt} / \mathrm{ZrO}_{2} / \mathrm{n}$-Si anode is employed as anode electrocatalyst for efficient ethanol oxidation. The Pt/ $\mathrm{ZrO}_{2} / \mathrm{n}$-Si anode shows high EOR catalytic activity with reasonable peak current density $\left(11.08 \mathrm{~mA} \mathrm{~cm}{ }^{-2}\right)$. When exposed to the visible light irradiation, the $\mathrm{Pt} / \mathrm{ZrO}_{2} / \mathrm{n}$-Si anode exhibits the apparently improved EOR performance with the higher peak current density $\left(24.46 \mathrm{~mA} \mathrm{~cm}{ }^{-2}\right)$, the lower onset potential and the better stability. The excellent performance can be 
attributing to the synergistic effects of electro- and photocatalytic during the EOR processes. This low-cost and highperformance photo-assisted anode, demonstrating that Si has the potential to be used in photo-assistant ethanol oxidation reaction.

\section{Acknowledgements}

This work was supported by Fujian Institute of Research on the Structure of Matter, Chinese Academy of Sciences, the National Natural Science Foundation (NSF) of China (No. 61674152), and the NSF of Fujian Province (No. 2017J01130).

\section{Notes and references}

1 H. A. Gasteiger and H. M. Marković, Just a dream-or future reality?, Science, 2009, 324, 48-49.

2 B. C. Steele and A. Heinzel, Materials for fuel-cell technologies, Nature, 2001, 414, 345-352.

3 M. K. Debe, Electrocatalyst approaches and challenges for automotive fuel cells, Nature, 2012, 486, 43-51.

4 E. Antolini, Catalysts for direct ethanol fuel cells, J. Power Sources, 2007, 170, 1-12.

5 F. A. De Bruijn, V. A. T. Dam and G. J. M. Janssen, Review: durability and degradation issues of PEM fuel cell components, Fuel Cells, 2008, 8, 3-22.

6 J. Greeley, I. E. L. Stephens, A. S. Bondarenko, T. P. Jhansson, H. A. Hansen, T. F. Jaramillo, J. Rossmeisl, I. Chorkendorff and J. K. Nørskov, Alloys of platinum and early transition metals as oxygen reduction electrocatalysts, Nat. Chem., 2009, 1, 552-556.

7 M. A. F. Akhairi and S. K. Kamarudin, Catalysts in direct ethanol fuel cell (DEFC): an overview, Int. J. Hydrogen Energy, 2016, 41, 4214-4228.

8 X. Q. Huang, Z. P. Zhao, L. Cao, Y. Chen, E. B. Zhu, Z. Y. Lin, M. Li, A. M. Yang, A. Zettl, Y. M. Wang, X. F. Duan, T. Mueller and Y. Huang, High-performance transition metal-doped $\mathrm{Pt}_{3} \mathrm{Ni}$ octahedra for oxygen reduction reaction, Science, 2015, 348, 1230-1234.

9 A. Kowal, M. Li, M. Shao, K. Sasaki, M. B. Vukmirovic, J. H. Zhang and R. R. Adzic, Ternary Pt/Rh/SnO electrocatalysts for oxidizing ethanol to $\mathrm{CO}_{2}$, Nat. Mater., 2009, 8, 325-330.

10 A. L. Wang, X. J. He, X. F. Lu, H. Xu, Y. X. Tong and G. R. Li, Palladium-Cobalt Nanotube Arrays Supported on Carbon Fiber Cloth as High-Performance Flexible Electrocatalysts for Ethanol Oxidation, Angew. Chem., Int. Ed., 2015, 54, 3669-3673.

11 C. Y. Su, Y. C. Hsueh, C. C. Kei, C. T. Lin and T. P. Perng, Fabrication of high-activity hybrid Pt@ZnO catalyst on carbon cloth by atomic layer deposition for photoassisted electro-oxidation of methanol, J. Phys. Chem. C, 2013, 117, 11610-11618.

12 K. Drew, G. Girishkumar, K. Vinodgopal and P. V. Kamat, Boosting fuel cell performance with a semiconductor photocatalyst: $\mathrm{TiO}_{2} / \mathrm{Pt}-\mathrm{Ru}$ hybrid catalyst for methanol oxidation, J. Phys. Chem. B, 2005, 109, 11851-11857.
13 T. Wang, J. Tang, S. C. Wu, X. L. Fan and J. P. He, Preparation of ordered mesoporous $\mathrm{WO}_{3}-\mathrm{TiO}_{2}$ films and their performance as functional $\mathrm{Pt}$ supports for synergistic photo-electrocatalytic methanol oxidation, J. Power Sources, 2014, 248, 510-516.

14 K. Sun, S. Shen, Y. Liang, P. E. Burrows, S. S. Mao and D. Wang, Enabling silicon for solar-fuel production, Chem. Rev., 2014, 114, 8662-8719.

$15 \mathrm{~S} . \mathrm{Hu}, \mathrm{M}$. R. Shaner, J. A. Beardslee, M. Lichterman, B. S. Brunschwig and N. S. Lewis, Amorphous $\mathrm{TiO}_{2}$ coatings stabilize $\mathrm{Si}$, GaAs, and $\mathrm{GaP}$ photoanodes for efficient water oxidation, Science, 2014, 344, 1005-1009.

16 Y. W. Chen, J. D. Prange, S. Dühnen, Y. Park, M. Gunji, C. E. Chidsey and P. C. McIntyre, Atomic layer-deposited tunnel oxide stabilizes silicon photoanodes for water oxidation, Nat. Mater., 2011, 10, 539-544.

17 A. G. Scheuermann, J. P. Lawrence, K. W. Kemp, T. Ito, A. Walsh, C. E. Chidsey and P. C. McIntyre, Design principles for maximizing photovoltage in metal-oxideprotected water-splitting photoanodes, Nat. Mater., 2015, 15, 99-105.

$18 \mathrm{C}$. W. $\mathrm{Li}$ and $\mathrm{M}$. W. Kanan, $\mathrm{CO}_{2}$ reduction at low overpotential on $\mathrm{Cu}$ anodes resulting from the reduction of thick $\mathrm{Cu}_{2} \mathrm{O}$ films, J. Am. Chem. Soc., 2012, 134, 7231-7234.

19 H. Yang, J. Zhang, K. Sun, S. Zou and J. Fang, Enhancing by weakening: electrooxidation of methanol on $\mathrm{Pt}_{3} \mathrm{Co}$ and $\mathrm{Pt}$ nanocubes, Angew. Chem., 2010, 122, 7000-7003.

20 A. Leelavathi, G. Madras and N. Ravishankar, New insights into electronic and geometric effects in the enhanced photoelectrooxidation of ethanol using $\mathrm{ZnO}$ nanorod/ ultrathin au nanowire hybrids, J. Am. Chem. Soc., 2014, 136, 14445-14455.

21 L. Han, S. Guo, M. Xu and S. Dong, Photoelectrochemical batteries for efficient energy recovery, Chem. Commun., 2014, 50, 13331-13333.

22 S. M. Fang, X. Dong, Y. Zhang, M. Kang, S. L. Liu, F. Yan, L. He, X. Feng, P. Wang and Z. H. Zhang, One-step synthesis of porous cuprous oxide microspheres on reduced graphene oxide for selective detection of mercury ions, New J. Chem., 2014, 38, 5935-5942.

23 Y. Zhu, H. Uchida, T. Yajima and M. Watanabe, Attenuated total reflection-Fourier transform infrared study of methanol oxidation on sputtered Pt film anode, Langmuir, 2001, 17, 146-154.

24 C. Y. Zhai, M. S. Zhu, D. Bin, H. W. Wang, Y. K. Du, C. Y. Wang and P. Yang, Visible-light-assisted electrocatalytic oxidation of methanol using reduced graphene oxide modified $\mathrm{Pt}$ nanoflowers- $\mathrm{TiO}_{2}$ nanotube arrays, ACS Appl. Mater. Interfaces, 2014, 6, 17753-17761.

25 H. Lu, J. Zhao, L. Li, L. Gong, J. Zheng, L. Zhang, Z. Wang, J. Zhang and Z. Zhu, Selective oxidation of sacrificial ethanol over $\mathrm{TiO}_{2}$-based photocatalysts during water splitting, Energy Environ. Sci., 2011, 4, 3384-3388.

26 C. Jia, H. Yin, H. Ma, R. Wang, X. Ge, A. Zhou and Y. Ding, Enhanced photoelectrocatalytic activity of methanol oxidation on $\mathrm{TiO}_{2}$-decorated nanoporous gold, J. Phys. Chem. C, 2009, 113, 16138-16143. 
27 J. Despres, M. Elsener, M. Koebel, O. Kröcher, B. Schnyder and A. Wokaun, Catalytic oxidation of nitrogen monoxide over Pt/SiO ${ }_{2}$, Appl. Catal., B, 2004, 50, 73-82.

28 K. D. Schierbaum, S. Fischer, M. C. Torquemada, J. L. de Segovia, E. Roman and J. A. Martín-Gago, The interaction of Pt with $\mathrm{TiO}_{2}$ (110) surfaces: a comparative XPS, UPS, ISS, and ESD study, Surf. Sci., 1996, 345, 261-273.

29 N. S. McIntyre, D. D. Johnston, L. L. Coatsworth, R. D. Davidson and J. R. Brown, X-ray photoelectron spectroscopic studies of thin film oxides of cobalt and molybdenum, Surf. Interface Anal., 1990, 15, 265-272. 